\title{
is design finished? dematerialisation and changing things
}

\section{Cameron Tonkinwise}

tull screen print

page 123456789101112131415

An 'object' is what gets in the way, a problem thrown in your path like a projectile (coming as it does from the Latin objectum, Greek problema)... I come across obstacles in my path (come across the objective, substantial, problematic world); I overturn some of these obstacles (transform them into objects of use, into culture) in order to continue; and the objects thus overturned prove to be obstacles in themselves. The more I continue, the more I am obstructed by objects of use... Vilém Flusser 'Design: Obstacle for/to the Removal of Obstacles' 1$]$

How will things end? With things. The world, modern apocalyptic tones sing, will seize up with a surfeit of stuff.[2] An unending stream of products will finish it all off, jamming the workings of the life-flow: a cataclysmic deluge leading to an irreparable breakdown.

Where do all these things come from? From designers, but why? Why do designers keep making things? Why do we keep making designers make more things?

How is it that things just seem to build up in our households? And then in storage spaces that we rent to keep all the things we do not need on a daily basis? Almost imperceptibly, things accumulate. One day we find to our surprise that we have three of the same thing: one old but still working; one not so old but not working; one new but difficult to make work. Or else: one that does one thing; one that does that same thing and something else that we never need; and another that can do that thing and many others if only we knew how. How did we get into this situation? Why are there so many variations of the same thing? Why is it someone's job, someone's specialist expertise to search for new things to make, to find inadequacies with some existing thing as a weak premise for designing yet another version of that thing? Why is it a novel subcultural phenomenon when 'downshifters' take lifechanging actions to reduce the number of things they have? Why is it profoundly challenging when sustainability policy innovators talk of reducing the number of things we need to own by promoting systems of shared-use? In fact, the real issue in regard to the unsustainability of our households is not just the number of things in them (and our rented storage adjuncts) at any one time. It is less our standing stock than our throughputs. It is the number of things that pass through our households over time, the linear flow from raw materials to junk of near zero-life products, to use Walter Stahels' terminology. 4he unsustainable rate of flow in this 'river economy' results less from increasing amounts of disposables like packaging, than the increasing percentages of things we treat as disposables. Semi-durables slide 
toward single-use, and durables toward semi-disposables. In most of these cases, we are passing on for storage in land-fill not broken, but just redundant things. How is this possible? How is that we spend so little time with things we invest so much in purchasing? How can we without conscience relegate such sophisticated technical materials and devices to abandonment? What are these things that designers design, these things that we desire only to dispose of, these things that seem to disappear the moment they arrive?

\section{actively relating to things}

Yet the tragedy is that in the moment homo faber seems to have found fulfilment in terms of his own activity, he begins to degrade the world of things, the end and end product of his own mind and hands; if man the user is the highest end, 'the measure of all things,' then not only nature, treated by homo faber as the almost 'worthless material' upon which to work, but 'valuable' things themselves have become mere means, losing thereby their own intrinsic 'value'

Hannah Arendt The Human Condition [5]

Thankfully, sociologists are beginning to develop more sophisticated accounts of our relations to the stuff we have derelict about us. Until recently, sociologists were their own worst enemies, borrowing impoverished concepts like 'consumers' from culturally vacuous disciplines like economics to explain 'thing accumulation and flows'. The results were laments about the inevitability of consumerism ('it's human nature to be addicted to novelty'; 'it's the essence of social relations to consume conspicuously'; 'it's the structure of capitalism to amass material property'), when in fact this determinism was only the consequence of such stereotyping.

Instead, recognition is now emerging that everyday life involves a wide variety of purchase, use and disposition processes; some are psychological, some social, some functional; many involve tacitly negotiated combinations of all these domains; nearly all are structured by the particularities of a range of meso-level activities, tasks that are not dissociable from various interrelated products. If things multiply through our households, this has less to do with spectacular moments of consumerism than our many and varied everyday habits: preparing food, entertaining ourselves with or without others, getting to and from people and places, clothing ourselves cleanly for different contexts. I am thinking for example of analyses of 'unconscious consumption' like Elizabeth Shove's Comfort, Cleanliness and Convenience: The Social Organization of Normality. 0 . Her first survey chapter is a critique of consumption sociology and sustainability research to date for overemphasising and isolating "moments of acquisition rather than the consequent adjustment of what people do. [Her question is instead] So how does the stuff and substance of consumption relate to the ordering of everyday life and to concepts of normal and proper practice?" .(14) Her response is to invoke actor network theory to explain the shifting historical coconfigurations of users and their products into distinct patterns of use and disposition.

It is in the context of these recent activity-based accounts of our 'thing relations' that the following was developed. In negotiating things as pragmata, "things insofar as we have to do with them at all, whether we work on them, 
use them, transform them, or we only look at and examine them," these accounts have not only surpassed the inadequacies of consumer analyses, but they have also opened up better understandings of the relation of design to the unsustainability of our stocks and flows of stuff.

Mostly without knowing it, these accounts of the everyday purchase, use, neglect and disposal of things derive from the phenomenology of lived practice initiated by Martin Heidegger's existential analytic. Things in that account are first of all networked equipment manifesting only within the 'inorder-to' of certain activities. However, whilst these recent more praxeological accounts of household consumption take up a Heideggerian perspective, there is level to which they are yet to proceed. Without moving to that level, which probably means explicitly negotiating their Heideggerian heritage, what these analyses have to say does not add up. Their case studies of the plurality of everyday thing relations do not yet go to answering the questions with which I began, about the net volume of things that our houses hold for more or less time. So what follows is an attempt to outline what an analysis at that level entails. It is an attempt to explicate the thingliness of the things designed for us to use each day. It tries to show how that thingliness makes possible, and even necessary, things made for long lives yet limited use, things that can therefore accumulate, whether in our houses or in landfills, without us even caring.

\section{mis-taking things}

In the hierarchy of things from which I just cited, Heidegger asserts that pragmata is second last to mathémata. This more fundamental level of thinking about things is crucial, Heidegger believes, for understanding the state of things in our world today. His 1935-6 lecture course on The Question Concerning the Thing 8 argues that Kant completes a shift, effected in large part by Newtonian physics, in the meaning of the mathematical that essentially moves things from the realm of the qualitative to the quantitative. Eytmologically, the mathematical refers not to numbers and the algebraic or geometric, but rather to "things insofar as we learn them" (71) or rather "things insofar as we take cognizance of them as what we already know them to be in advance" (73) Things can only be encountered as things if there is prior characterisation of them as some sort of thing. "The mathematical is that evident aspect of things within which we are always already moving and according to which we experience them as things at all, and as such things. The mathematical is the fundamental position we take toward things by which we take up things as already given to us, and as they should be given. Therefore, the mathematical is the fundamental presupposition of the knowledge of things." (75)

So the mathematical is the fore-understanding by which things come to be the things we experience them as. If things are experienced pragmatically, as being(s)-of-use, this way of being a thing derives from a particular 'mathematics' of things. According to Heidegger, this is in fact the original Greek mathematics of things. Whilst we today still do live with things within this mathematics, this is not how we explicitly think about things. Modern things by contrast are distanced from practical experience. They are instead taken to be mere manifestations of abstract systems of physics and 
chemistry. We moderns, after Galileo, Newton, Descartes and Kant, 'experience' things as so many substitutable examples of certain properties and relations. Ancient anticipatory learning has become modern projective instruction, "a project (Entwurf) of thingness which, as it were, skips over things... a basic blueprint [that] at the same time provides the measure for laying out of the realm, which, in the future, will encompass all things of that sort" (96). (9] Engagement with particular things through practical understanding of their distinct qualities is thereby replaced by designed calculations of numbers of things. To be crude, customised thingly relations are replaced by mass production.

This account of the changing mathematics of things is an elaboration of the account in Being and Time of the shift from praxis to theoria, from 'how-to'based concern with the ready-to-hand to 'what is' observatory operations on the present-at-hand. 10" And, in nascent form, this account of the changing mathematics of things links also to Heidegger's later critique of technology where, beneath the imperialism of instrumental reason, things lose their engaged specificity and are instead quantified as mere means to unquestioned ends.

However, this last linkage is too quick a paraphrase of Heidegger's critical account of the technological metaphysic. It is a misinterpretation that glosses over precisely the issue of things. It suggests that the accumulation and flows of things through our households is the result of instrumentalism. Pure instrumentalism though should, in all efficiency, aim to involve no things at all. According to this understanding of Heidegger's critique, as we become more enthralled by technology we should become literally more metaphysical. We should have less and less to do with material things as we become more concerned with the modern sense of the mathematical: the digital, information, systems. But instead we find the opposite. We find the paradox that Ezio Manzini has noted that the more involved we are with the immaterial, the more material things accumulate as junk about us. A merely instrumentalist understanding of technology cannot explain this incessant materialisation.

This mistaken version of Heidegger is particularly pertinent at this moment when sustainability researchers have begun promoting the design of sustainable service-systems as a strategy for lowering the material intensities of our societies. 12$]$ These service-systems aim to deliver functional results with the minimum material inputs over time. Whilst to a naïve Heideggerian these service-systems might appear to be worrying exemplars of technological Gestell, the dangerous enframing of all beings within sheer functionality, the immediate outcome of such an enframing, according to such a reading, should indeed be dematerialisation. Being-in-the-world could, according to this inadequate understanding of Heidegger, through servicesystem design, become a thingless process, a situation in which things become completely efficient substrates satisfying changing human wills. However, with a more thorough understanding of Heidegger, particularly of the fact that Heidegger's critique of technology emerges from his account of thingliness, functional innovations through service-systems can be read as one of those predictions - like those of the coming service society, 
information revolution, knowledge economy, or post-materialist values - that will be buried beneath so much stuff.

To put this another way, if the abridged Heidegger-on-technology account is too broad - and in fact not dissimilar to the stereotyping of consumerism and yet the pluralist pragmatic account of everyday consumption activities too narrow, what lies between is in fact design. The mathémata that structure our pragmata result not only in chrémata "things insofar as they are in use and therefore stand at our constant disposal", but also poioúmena, "things insofar as they are produced by the human hand and stand as such." (70) And it is within the ontology of making, the techné of poiesis that a certain mathémata takes place that accounts for things as they accumulate and flow unsustainably today. But to access this, poioúmena must be compared with the last (or in fact first) category of things, phusiká.

\section{finishing things off}

The work of our hands, as distinguished from the labour of our bodies... fabricates the sheer unending variety of things whose sum total constitutes human artifice. They are mostly, but not exclusively, objects for use and they possess the durability Lock needed for the establishment of property... It is this durability which gives the things of this world their relative independence from me who produced and use them, their 'objectivity' which makes them withstand, 'stand against' and endure, at least for a time, the voracious needs and wants of their living makers and users.

Hannah Arendt The Human Condition [13]

Martin Heidegger's 1939 essay "On the essence and concept of Phüsis in Aristotle's Physics B I" 14 is is helpful in this matter. Heidegger's essay aims to recover a sense of kinesis or 'movedness' as the essence of all being. [15] Most radically, Heidegger tries to demonstrate that, in terms of phüsis; all things are in motion, especially those concrete everyday things which we moderns think are 'at rest':

But are bedsteads and garments, shields and houses moving things? Indeed they are, but usually we encounter them in the kind of movement that typifies things at rest and therefore is hard to perceive. Their 'rest' has the character of having-been-completed, having-been-produced, and, on the basis of these determinations, as standing 'there' and lying present before. Today we easily overlook this special kind of rest and so too the movedness that corresponds to it, or at least, we do not take it essentially enough as the proper and distinguishing characteristic of the being of these beings. And why? Because under the spell of our modern way of being, we are addicted to thinking of beings as objects and allowing the being of beings to be exhausted in the objectivity of the object. (192)

To reveal this 'movedness', Heidegger is at pains to refuse the common misinterpretation of Aristotle, that the difference between phüsis and techné is that between the autopoietic and the allopoietic. What we today call 'nature' is not that which makes itself, as opposed to everything else which is the product of human making, i.e. the 'artefactual', because phüsis is in no way a form of making. The difference lies not in who or what does the making, but between the completed product of making and what just is. 
Now, in typical Heidegger fashion, this distinction is the opposite of what it at first seems. In terms of movedness, the previous quotation indicated that things that are a result of poiesis or (human) making, e.g., bedsteads and the like, are at rest. They lie present (are pre-sent), finished. By contrast, phüsical things just are, but in a way that manifests a dynamic presence (a presencing). Far from being cast as something permanently present, phüsis must be understood as always already in formation; at any one time phüsical things are capable of being some things and resisting being others; at every moment they are becoming and withdrawing (at the same time, i.e. becoming $X$ by withdrawing from being $Y$ ).

Heidegger notes that to 'lead the way toward' this sense of being phüsically, Aristotle invented a term: entelécheia. Heidegger translates this term as 'holding (echel) itself (en) in its end (telos)' (217). Again, meaning the opposite of the way it is immediately read, entelécheia designates not that which has reached its end, as if its end were different from what it has, up until that time, been, but that which is, at all times in its becoming, what it is and aims to be. With this term, a clear distinction can now be drawn between the outcomes of techné and phüsis.

A table is not a table until it is finished. It is not what it aims to be (its telos) until it is completed (by a maker, arché, who also happens to lie outside it, but this is merely contingent, not axial to what differentiates phüsical and technical things). When it is done, when the making is over, the table (as opposed to the phusical wood - this is the whole point, so I will come back to this) has no becoming but instead is finished. It is (at) an end; it is 'finishedly'. This is very different to a tree, which is never over and done with. It is always still on-the-move. 10 However, though forever 'on the way', it is nevertheless always also what it aims to be. Though never completed, the tree is at every moment complete as a tree. Even when a sapling, a seedling, or a seed, and also when rotting wood, it is never (at) an end, but rather has its end as and in what it is. 71 Where techné aims to finish (making) something, phüsis involves things being sustained, that is, the maintenance of things, in their changingness, continuing their change, or their continuance by changing themselves.

\section{disposing of what is taken for granted}

Commercial competition has pushed forward the most rapid employment of these possibilities [of the fluidification of matter], leading to the multiplication of images and services offered and to the accelerated introduction of the 'new'. At the same time, the lack of a design culture capable of confronting these new technological possibilities has resulted in the dissemination of worthless products. So the potential of the old technology is distributed in the banal forms of gadgets, disposable products, and ephemeral objects lacking any cultural significance. A feeling of generalized transcience, an impoverishment of sensory experience, of superficiality and the loss of relations with objects derives from this; we tend to perceive a disposable world: a world of objects without depth that leaves no trace in our memories, but does leave a growing mountain of refuse.

Ezio Manzini "Prometheus of the Everyday" 181 
Heidegger's efforts at recovering the Aristotlean sense of phüsis are undertaken out of a fear that we moderns are losing our ability to affirm the movedness of that which is in a state of becoming. A productivism, that is, a propensity to see everything as technical, as if it had all been produced (i.e. the product of a Creator), casts things into certain (Platonic) metaphysics of presentness. The danger in mis-seeing everything about us as only products is that every thing is then mis-taken as being finished, as completely static. We stop seeing things in motion, or motion in all things, and instead see only objects. What is problematic is less seeing everything as a mere means, than seeing everything as an end; or rather, things can only be exploited as mere means if they appear to have no inherent process of their own, if their becoming is thought to have ended. These products are reduced to being just what they are, that is, just how they are now, in the present.

This then is why Heidegger must remind us of the in-time-ness of being. As the technical producer of things, humans seem to let all that they encounter lapse into being merely beings, things just present, as if outside time. These 'out-of-time' things tend to be merely present things, not impressively there, shining forth in their thereness at the moments when they are here. This is because their not-always-having-been- and not-always-will-be-hereness is also not being noticed; the way these things are only whiling here, their phusical coming-to-be and unbecoming, is not acknowledged as being also there along with them. To this extent, produced things, as finished, as merely present, lose their having-been-produced-ness. They are alienated from their production and reified as sheer stuff. In other words, it is in the very nature of production that production erases itself by its outcome. The result of poiesis are things that deny their poietic nature. As such, as just present things, now here as if from nowhere, these things become constantly present, there at hand, to be added or multiplied as so much maths, to accumulate or flow without anybody taking care of them.

There is then a transition in the nature of things accomplished by techné:[19]

- from "the real [Wirkliche] [as] the working, the worked [Wirkende, Gewirkte]; that which brings hither and brings forth into presencing, and that which has brought forth and brought hither... the presencing, consummated in itself... entelecheia" (160)

- to the real as "that which results from an operatio... that which follows out of and follows upon an actio,: the consequence, the out-come [Er-folg] ... that which follows in fact and... is the factual [Tatsächliche]" (161-2)[20]

- then to "the real now show[ing] itself as object, that which stands over against [Gegen-Stand]... We shall now name the kind of presence belonging to that which presences that appears in the modern age as object:

objectness" (162-3) [21]

- and finally, "Objectness changes into the constancy of the standingreserve, a constancy determined from out of Enframing [a reference to Heidegger's famous 'The Question Concerning Technology']' (173).

In another essay from the same period, [22] Heidegger explains this 'constancy' via Rilke: 
The objectiveness [Gegenständige] of the world becomes constant [ständig] in representational production... In this, it is true, there is another transformation of things into the inward and invisible. However, this transformation substitutes for the frailty of things the factitious constructions of calculated objects. These objects are produced for consumption. The more quickly they are consumed, the more necessary it becomes to replace them ever more quickly and easily. That which is enduring about the presence of objective things is not their resting-in-themselves in their own world. What is constant about things produced as mere objects of consumption is the substitute [Ersatz].

I have cited extensively here because it is crucial to see the particular way in which the technical making of things leads both to the permanent materialisation of things and to the unceasing generation of things of only passing significance. It is the very finishedness of modern-(un)made things, the way they are cast out into the world as from then on unchanging, that, far from granting them long lives, destines them to be a never finished stream of short use-life objects requiring mathematical systems of collection, storage and disposal. They can be cycled through in a relay of never complete means only because they are technical end(ing)s. In this context, consumerism does not drive manufacturing, rather manufacturing drives consumption; not in the sense that the machinery of capitalism forces us to consume its products (through advertising for example, or design), but in the sense that making complete things (like the design of any product), making things whose thingliness lies in their completeness, in their being finished objects, leads to things of no particular lasting value. For the same reason, it is not the abstraction of mathematics, the calculative worldview of modern science, that strews our world with stuff; rather, it is the project of making things end that makes possible an abstractly quantitative way of dealing with all that results; theoretical science is a consequence of seeing things as inert products.

\section{sustaining things while presenced}

We are beginning to become conscious of the temporal nature of all forms (and thus of all creation). Since entropy is beginning to obstruct us at least as much as objects of use are. The question of responsibility and freedom (this being the essential question of creation) arises not only in the process of designing but also in the process of throwing away objects of use. It may be that consciousness of the temporality of all creation (even that of immaterial designs) will contribute to a future situation in which things will be designed a bit more responsibly, resulting in a culture with less and less room for objects of use to act as obstacles and more and more room for them to serve as vehicles for interpersonal contact.

Vilém Flusser 'Design: Obstacle for/to the Removal of Obstacles'[23]

Now, all this is how things are treated, but it is not how they are. As Heidegger famously revealed in Being and Time, we are constantly surprised by things not being constantly there for us. We only notice things' being, and the being of poioúmena as having-been-produced, when they break down. At these times, products re-assert their being-in-time, withdrawing phüsically from the technical system into which they have been requisitioned. I say phüsically because these moments that defy the finishedness of things manifest the 
materiality of things - or more, precisely, manifest things as alive, as matterin-motion, energised, entelechially underway.

This has frustrating consequences for our no-time-out economy, but our anguish on these occasions evidences the extent to which we expect and depend upon products being unchangingly perfect. If we were Presocratics, we would, according to Heidegger, consider such wear and tear thenorm rather than the exception; we would live in the awareness that it is the nature of all things to egress, evade and elude, rather than stay put, no matter how technologically sophisticated we get.[24] And in fact, if we were Ancient Greeks, so tolerant would we be of this withdrawal of things that we would consider products of poiesis to be merely at rest, not unmoving, merely whiling in a particular presence, rather than permanently present; finished in a particular way, but in no way entirely complete, or wholly at an end.

In short, to be Greek about things would mean actively sustaining things, paying respect to the things we have brought to presence with and for us, by preserving them while they are here. Exactly as modern overemphases of products' permanence means that that things are ignored, neglected, stored in places we never go or accelerated through our households as quickly as possible, so ancient awareness of products' impermanence means spending time with things, maintaining and repairing them, sustaining them.

We are now in a position to see why this engagement with Heidegger on things is significant. Only a consideration of the mathematical level of things as finished products explains both how consumerism is possible and why it is unsustainable. Consumerism emerges as a fundamental inability to sustain things. It is a refusal to acknowledge that artificial things remain natural to the extent that they are within time, aging. It is refusal to see that making does not make things permanent, but only ever holds things as particular sorts of things for particular periods of time. It is arefusal that cannot not leave refuse in its wake.

Further, only such a thingly account of our societies can explain why the things we use in our changing everyday activities increasingly take the paradoxical form of disposable durables. Without considering the mathematics of made things, one could expect that that things would conform to the activities for which they are used, changing when the activity changed, or being changeable, that is, maintainable and repairable, when the activity stayed the same. With a consideration of the mathematics of made things it is understandable why there should be such a mismatch between service-life of materials and components and actual product use-lives, why 'planned obsolescence' can be a design strategy in a way that 'waste management' or 'refurbishment, remanufacturing, recovery' never can. Plastic for example, that quintessential disposable durable can now be explained as the perfect technical product.

All this now also fits with several points about contemporary approaches to sustainability that were mentioned in passing at the outset:

Firstly, our unsustainable contemporary notion of things makes predictable that post-industrial societies would be characterised not by the replacement of things but rather the mere displacement of things. The production of things could not just end but was bound to rebound, finding more ways to 'continue thinging completely'. 
Secondly, this is why the unsustainability of things lies in both the stock of things in each of our households and the flow of things through those households. Stocking and flowing are the same thing if things are neverending ends.

Thirdly, and most pertinently for the context of this issue of DPP, PSS (product service systems) design will be another thing to get rid of unless it is explicitly an engagement with the timing of things. This means that PSS design must focus on what is being categorised as 'product-oriented services', services that aim to extend and/or intensify the use-life of things. [25] To put this in terms of households, given that shortening product use lives are one of the most unsustainable things about our everyday lives, our materials intensity can be reduced by slowing the throughput of things, by making things last longer. Given that increased material inputs to a product are one of the most direct ways of enhancing durability, this means that, given sufficiently designed product life extension, rematerialisation can be a dematerialisation strategy. From the mathematico-philosophic point of view of this article, the most directly unsustainable thing about our households is the throughput of disposable durables, and so the only appropriate strategy consequently is the re-thing-ification of things, that is to say, the retemporalisation of things.

\section{servicing imperfectly moving things}

In the very moment in which technological innovation affects a loss of many limits to our possibilities, society has begun to realize that other limits we had not previously recognized exist. The 'discovery' of environmental limitations and their implications is certainly another

aspect that characterizes the current historical phase and requires a profound reconsideration of the meaning that we have thus far given to the verbs design and produce... One passes from a 'culture of doing as production' to one of 'doing as reproduction.' It concerns moving toward a production culture in which human activity has as its primary objective the regeneration of the conditions that permit, and will continue to permit, the continuation of existence.

Ezio Manzini "Prometheus of the Everyday" [26]

Heidegger's Aristotelian brief awaiting designers in the age of a surfeit of stuff is then clear. Design timely things, things that can last longer by being able to change over time. Design things that are not finished, things that can keep on by keeping on being repaired and altered, things in motion.

Importantly, this is a different brief to the perennial exhortations for quality design. Calls for product-life extension by design have echoed throughout the twentieth century from the Werkbund, through Vance Packard and the Committee for Terotechnology, to EternallyYours. [27] In many ways each of these, and many others, was advocating still, or even more so, perfect things [per-ficere: to bring to an end]. The cliché of the design classic signals exactly that its objective is an ahistorical, timeless product. The contemporary, purely technical version of this mathematics aims at the unchanging through nanotechnology - the self-repairing, self-altering, self-reproducing. (Plastic; 
artificial intelligence; nuclear energy; how many of these promethean moments must we continue to fail to learn from?)

By contrast, the Heideggerian brief is for the imperfect product, the product that must be continuously improved, the product that is always still under development, a work in progress. Or more precisely, product-plus: 28 product plus a process that takes responsibility for the fact that the product in its present manifestation, in its materiality, is not the be-all-and-end-all, but must be actively sustained. As indicated in the previous section, this is a PSS, but one that exists to enhance rather than distance things.

An instructive version of this kind of brief was provided by Abraham Moles in the late ' 80 s (in English), before the discourse of sustainability was established. Moles was not writing from a Heideggerian context of course, but instead responding to hopes of a coming post-industrial society with the uncharacteristic realisation that "Any immaterial civilization will be heavily materialized because its immaterial products are necessarily linked to the mechanical infrastructure that generates, stabilizes and governs them". 290 Moles recognized that "The immaterial civilization must be reliable" (27), and that that reliability comes not from creating "new' objects' (31) but from "amaintenance mentality" (26).

In another article, Moles concretizes what this poietic mathematics would entail with a proposal for "The Comprehensive Guarantee" 30 : that all bills of sale be accompanied by a contract ensuring not only full repair whenever needed but also compensation for inconvenience and loss of product use time. Prescient of current arguments about 'extended producer responsibility', Moles foresaw that such a performance contract would reflect back upon the design process. Designing products for servicized use-life extension means "tak[ing] into account the micropsychological analysis of the object/user binome and deduc[ing] from each aspect of this interaction not only the conditions in which the object will fulfil what was traditionally called its function, but also the conditions of its permanence [my italics] with respect to the role it is to play in the life of the user" (64). The task for designers then according to Moles is to design the sustainment of what they design; to design not just some thing, but also the conditions through which that thing has a presence over time as a thing; that is to say, to design how a thing things.

\section{overcoming product fixation}

The look, eidos, and the form, morphe, each encloses within itself that which belongs to a thing. As enclosing, it constitutes the limiting boundary of what determines the thing as finished, complete. The look, as enclosing the belongingness of all the real determinations is also conceived of as constituting the finishedness, the completeness, of a being.

Heidegger The Basic Problems of Phenomenology [31]

I would like to end with the question of whether designers are fundamentally capable of negotiating this brief. 
What is at issue is not whether designers are capable of designing nothings rather than things, that is to say, services rather than products, $[32]$ but rather whether designers are capable of designing things that are not finished. It is less a matter of designing a different sort of thing than a matter of a thoroughly different form of designing, one that is perhaps better described as form of 'continuous design' or 'redesigning'.

There is at first the psychological obstacle to this imperfectionism. Nuri Bilgin, in an article upon which Moles relies for much of what he advocates in relation to the 'comprehensive guarantee', points out that maintenance tends to work against certain psychological theories that argue that "any motivation toward completing a task engenders tension, which is usually relaxed only when the task has been accomplished. Now, since prevention is carried out without perceptible stimuli and without a direct goal, this state of tension persists, and the preventive action may bring about permanent frustration." 34 ] In other words, would designers find satisfying enough the production of incomplete products to complete the process of designing, creatively? There are then the anthropological obstacles surrounding homo faber. From a Marxist perspective, the essence of being human is to externalize oneself through material production; without an alienated object as outcome, humans are reduced to animality without identity.

But more pertinent to this article is the ontology of designing. If designing is making par excellence, the project of pre-determin(at)ing what is to be made present, what can be considered actually complete when that form is materialized, then designing is mathematical in the modern sense through and through. A designing that could generate other sorts of changing things, things other than blueprinted ends, would no longer be a form a de-signing. So perhaps it is time that we finished designing.

Dr Cameron Tonkinwise is Director of Design Studies at the University of Technology, Sydney. He is also Convenor of the Society for Responsible Design and Director of its Change Design project. This article is a substantially reworked version of "Interminable Design: Techne and Time in the Design of Sustainable Service Systems', Proceedings of the 5th European Academy of Design Conference: Techne Design Wisdom Barcelona, Spain, May 2003.

Vilem Flusser The Shape of Things: A Philosophy of Design London: Reaktion 1999: 58,61

For one of the latest publications in this vein see the Worldwatch Institute's State of the World 2004: The Consumer Society Washington: Worldwatch Institute, 2004. 
Noorman, K. and T. Uiterkamp eds Green households? Domestic Consumers, Environment, and Sustainability London : Earthscan, 1998.

See for example, Stahel, W. "The Utilization-focused Service Economy: Resource Efficiency and Product-Life Extension" in Allenby, B. ed. The Greening of Industrial Ecosystems Washington: National Academy Press, 1994.

Hannah Arendt The Human Condition Chicago: University of Chicago Press, 1958, p155.

Elizabeth Shove Comfort, Cleanliness and Convenience: The Social Organisation of Normality Oxford: Berg, 2003. Page reference follows in the text of this paragraph.

Martin Heidegger What is a Thing? trans.W.Barton Jr. Chicago: Henry Regnery, 1967, p70. In what follows I am deliberately working through Heidegger's lesser known analysis of 'things' in this lecture course rather than his more famous earlier account of equipment in Being and Time and his equally famous later work on the "The Thing" as a fourfold. I am also working elsewhere through Heidegger's account of the thingliness of art in "The Origin of the Work of Art," a lecture contemporaneous with the What is a Thing? course. See Walter Biemel's "The Development of Heidegger's Concept of the Thing." The Southwestern Journal of Philosophy, n.XI (1980) pp47-64.

Page references are given in brackets in the text for this paragraph and the next. The lecture series was called "Basic Questions of Metaphysics: Kant's Doctrine of Transcendental Principles." It was published by Heidegger in 1962 (partly to counter an unauthorised and unauthored transcript that was circulating) under the title Die Frage nach dem Ding. I have altered the English title, What is a thing? in order to indicate the relation between this lecture course and Heidegger's more famous essay "Die Frage nach der Technik". Importantly, the original version of "The Question Concerning Technology" was as the second in a lecture series, the first of which was "The Thing."

I will return in the conclusion to the fact that Entwurf is perhaps better translated into English as 'design'.

\section{See Section 69 b in Division II, Part IV, pp357-64 (original pagination).}

The relation between Heidegger's early account of equipment and later account of technology has been explored by Hubert Dreyfus in "Heidegger's History of the Being of Equipment" in Dreyfus, H. \& Hall H. eds Heidegger: A Critical Reader [Oxford: Blackwell, 1992]. In relation to design, see also Carl Mitcham's "Dasein versus Design: The Problematics of Turning Making into Thinking" International Journal of Technology and Design Education no.11 (2001).

For the current state-of-the-art see the reports of the EU funded PSS thematic network, SusProNet at www.suspronet.org. 
A most recent translation is in McNeill, W. ed. Pathmarks Cambridge: Cambridge University Press, 1998. Page numbers are given in brackets in the text throughout this section.

Phüsis is conventionally translated as nature, and whilst Aristotle is primarily discussing 'nature' in the sense of 'living non-human things', the Ancient Greek can refer to all beings, as in the phrase 'the nature of all things' and Heidegger exploits this fact.

At other times, for example in "The Origin of the Work of Art" Heidegger promotes the more common term energeia (at work - ergon) rather than entelecheia to capture the moving-being of what is phusical. Energeia is the co-dependent obverse of dünamis. Heidegger insists that this doublet not be translated as 'actuality as opposed to possibility' since this utterly undoes the relation between the two terms, that is to say, the way that energeia involves the releasing of what is harboured as dünamis and vice versa. An image that Heidegger uses to explain this is the sprinter in the starting blocks, someone who is dynamically at rest, that is to say, in many ways more energised than when she lets go and simply lets that energetically carry her to the end of the race. In this way the sprinter is entelechially still a sprinter, or more precisely sprinting, even if not yet actually sprinting down the track. See Heidegger's lecture course Aristotle's Metaphysics Theta 1-3: On the Essence and Actuality of Force Bloomington: Indiana University Press, 1995.

Findeli reminds us that being able to see this 'metamorphosis,' being able to see the flower in the seed, is what defines the seeing beyond seeing (what is merely a temporal appearance) - or rather seeing before seeing, mathematically — that Goethe calls aesthetic intuition and which inspired much Bauhaus pedagogy properly understood. See for example, "Bauhaus Education and After: Some Critical Reflections" The Structurist vol.31-2 (1991-2), pp32-43.

In Buchanan, R. \& Margolin V. eds Discovering Design: Explorations in Design Studies Chicago: University of Chicago Press, 1995, p222.

The following sequence is taken from 'Science and Reflection' in Lovitt, W. ed. The Question Concerning Technology New York: Harper Torchbooks, 1977. Page numbers are given in brackets in the text in the following dot points. There are a number of similar lists in note form in "Sketches for a History of Being as Metaphysics" in The End of Philosophy trans. Joan Stambaugh New York: Harper and Row, 1973.

The translator notes (162) that the play on the stem 'deed' (Tat) cannot be translated, but it can, if one remembers that facere is 'to make'.

Translators note (163): 'Gegenständligkeit — not to be confused with Gegenständlichkeit (objectivity)'

'Why Poets' in Young, J. and K. Haynes trans. and eds Off the Beaten Track Cambridge: Cambridge University Press, 2002 pp 228, 231.

Op cit, p61. 
This is one of Heidegger's many ways of translating the 'Anaximander Fragment', taken here from the 1941 course, Basic Concepts [Bloomington: Indiana University Press, 1993], p.102.

This is the first of three ways of categorising PSSs according to the consensus position of SusProNet, the others being 'use-oriented services' such as leasing and sharing, and 'result-oriented services' such as performance contracts and no-build options or negawatts.

Op cit $\mathrm{pp} 222,235$

Vance Packard's The Wastemarkers (1961) made design synonomous with 'planned obsolescence.' The Committee for Terotechology was an initiative of the UK Department of Industry in 1975 aimed at promoting planned maintenance: see references to this in the OECD's Product Durability and Product Life Extension: Their Contribution to Solid Waste Management 1982. For an archive of the project of EternallyYours see: www. eternally-yours.com.

I have taken this title from a 'next-big-thing' management text: Christopher Lovelock's Product Plus: How Product + Service = Competitive Advantage New York: McGraw-Hill, 1994.

Moles, A "Design and Immateriality: What of it in a Post Industrial Society" Design Issues vol.4 no.s 1-2 (1988). Page references follow in brackets in the text in this paragraph.

Moles, A. "The Comprehensive Guarrantee: A New Consumer Value" Design Issues vol. 2 no. 1 (1985). Page references follow in brackets in the text in this paragraph.

\section{Bloomington: Indiana University Press, p 108.}

There are many for example now arguing that designers do have a role in a stuffed up society, as the designers of eco-services. Nicola Morelli, for instance, in a series of articles on methods for developing PSSs that extrapolate from his own experience in relation to the design of a telecommuting facility, maintains that whilst "from a design perspective the development of PSS represents a new challenge because the focus of the design activity shifts from the definition of new products to the re-organisation of existing elements on the basis of new needs and values... [nevertheless] designing a new PSS requires an extension [my italics] of the traditional designer's competence into new logical domains, such as the social construction of technological systems, market-oriented and organisational domains." Morelli, 2003, pp75,93. I do not mean to single out Morelli. The situation is the same with Tracy Bhamra and her colleagues then at Cranfield University: Bhamra et al., 2001; Argument, Lettice, Bhamra, 1998; van der Zwan \& Bhamra, 2001. Whilst noting that 'the development process for generating an 'alternative' [function fulfilment] solution is likely to be different from the product development process that is in place' (van der Zwan \& Bhamra, 2001: 4), the language that follows refers only ever to 'extra aspects', such as briefs that allow 'more design space' (4). When it is acknowledged that 'through this increased design space, the design processes 
themselves will change as well' (4), the latter is defined still as 'different tools and techniques' that deliver 'an 'alternative' solution' (4) based around the 'restructuring current product offers' (5). Morelli and Bhamra's belief that the generation of PSSs involves only extending designers rather than changing them has been recently backed by large scale EU research funding for the development of tools and techniques that designers can add to their processes in order that sustainable PSSs result.

I am referring here to John Chris Jones article "Continuous Design and Redesign" Design Studies vol.4 no.1 (January 1983). Though I am also reminded of Raymond Loewy's Never Leave Well Enough Alone. The difference is that between redesigning the very same thing, in its material uniqueness, and redesigning the same idea, each as replacement materialisation.

Nuri Bilgin "From an Industrial Society to a Maintenance Society" Impact of Science on Society vol.30 no.2 (1980), p.129. This reminds me, despite the severe disparity in contexts, of Christopher Alexander's concept of 'repair'. In Reyner Banham ed. Aspen Papers London: Pall Mall, 1974, Alexander advocates what might be called 'design for continual fine adjustment' (p93). In A Timeless Way of Building New York: Oxford University Press, 1979, Alexander differentiates the "patching, conservative, static" type of repair, returning things to their timeless "original state", from one that assumes "that every entity is changing constantly", in which case repair is "creative, dynamic and open", transforming what is being repaired into entelechial "new wholes" (485). 